\title{
The Effectiveness of Enhanced Primary Healthcare (EnPHC) Interventions on Type 2 Diabetes Management in Malaysia: Difference-in-differences (DID) Analysis
}

masliyana husin ( $\square$ masliyana@crc.gov.my)

National Institutes of Health https://orcid.org/0000-0002-6553-6012

Xin Rou Teh

Institute for Clinical Research: Institut Penyelidikan Klinikal

Su Miin Ong

Institute for Clinical Research: Institut Penyelidikan Klinikal

Yvonne Mei Fong Lim

Institute for Clinical Research: Institut Penyelidikan Klinikal

\section{Swee Hung Ang}

Institute for Clinical Research: Institut Penyelidikan Klinikal

Chee Lee Chan

Institute for Clinical Research: Institut Penyelidikan Klinikal

Ming Tsuey Lim

Institute for Clinical Research: Institut Penyelidikan Klinikal

Sunita Shanmugam

Institute for Health Management

Noraziani Khamis

Institute for Health Management

Faeiz Syezri Adzmin Jaafar

Institute for Health Management

Nor Idawaty Ibrahim

KKM: Kementerian Kesihatan Malaysia

Nazrila Hairizan Nasir

KKM: Kementerian Kesihatan Malaysia

Dian Kusuma

Imperial College Business School

Anita Katharina Wagner

Harvard Medical School

Dennis Ross-Degnan

Harvard Medical School

Rifat Atun

Harvard University HSPH: Harvard University T H Chan School of Public Health

Sheamini Sivasampu

Institute for Clinical Research: Institut Penyelidikan Klinikal

Original investigation

Keywords: Type 2 diabetes, primary health care, multifaceted intervention, clinical outcomes, quasi-experimental design, difference-indifference

Posted Date: January 28th, 2021

DOI: https://doi.org/10.21203/rs.3.rs-154502/v1 


\section{Abstract}

Background To evaluate the effectiveness of the Enhanced Primary Healthcare (EnPHC) interventions on process of care and intermediate clinical outcomes among type 2 diabetes patients. Research Design and Methods This was a quasi-experimental controlled study of multi-pronged interventions conducted in 20 intervention and 20 control public primary care clinics in Malaysia from November 2016 to June 2019. Malaysian patients aged 30 years and above with a diagnosis of type 2 diabetes were selected via systematic random sampling. We conducted difference-in-differences analyses of data on process of care and intermediate clinical outcomes extracted from medical records. Results We reviewed 12,017 medical records of patients with type 2 diabetes. Process of care measures improved: $\mathrm{HbA} 1 \mathrm{c}$ tests performed within the past three months (odds ratio (OR) 3.31,95\% Cl 2.13, 5.13); lipid test (OR 4.59, 95\% Cl 2.64, 7.97), LDL (OR 4.33, 95\% Cl 2.16, 8.70), and urine albumin (OR 1.99, 95\% Cl 1.12, 3.55) tests within the past year; BMI measured within the past six months (OR 15.80, 95\% Cl 4.78, 52.24); cardiovascular risk assessment (OR 174.65, 95\% Cl 16.84, 1810.80); and exercise counselling (OR $1.18,95 \% \mathrm{Cl} 1.04,1.33)$. We found no statistically significant changes in intermediate clinical outcomes. Conclusions EnPHC interventions were effective in improving process of care but not intermediate clinical outcomes for type 2 diabetes patients. The intervention package was successful in enhancing the quality of care in diabetes from the health provider perspective. Patient engagement and self-management support may be needed to bring forth changes in patient outcomes.

\section{Background}

Type 2 diabetes impacts individuals, health systems, and society by diminishing productivity [1] and increasing mortality[2]. In 2015, 415 million people worldwide ( 1 in 11 adults) lived with diabetes, with the estimated absolute global economic burden of 1.3 trillion U.S. dollars[3]. In Malaysia, approximately 1 in 6 adults had type 2 diabetes in 2015 [4] with an estimated yearly direct cost of over 600 million U.S. dollars [5]. This translates to $2 \%$ of Malaysian Growth Domestic Product (GDP), which is higher than the global cost of diabetes expressed as share of global GDP.

Despite medications with proven efficacy, studies from Malaysia and other regions of the world show that glycemic control is suboptimal $[6,7]$. For diabetes control, a continuum of services, including disease detection, treatment and monitoring need to be implemented. This sequence of services is referred to as the type 2 diabetes "cascade of care". Increasing engagement at all levels of the cascade may allow early detection and minimise morbidity and mortality from diabetes. A previous cascade of care analysis revealed that as many as $50 \%$ of individuals with type 2 diabetes in Malaysia were undiagnosed and even after receiving a diagnosis, only $22 \%$ had good glycemic control [8].

Integrated care models have been shown to improve patient satisfaction, perceived quality of care and access to care [9]. For type 2 diabetes care, integrated care models have been shown to reduce HbA1c levels in individuals with suboptimal control [10, 11]. However, most evaluations were carried out in high-income countries (HIC). The effectiveness of type 2 diabetes integrated care models is still inconclusive in low- and middle-income countries (LMIC) [12-15]. In addition to disease burden differences, the healthcare systems in these countries have different constraints and insufficiencies [16] relative to those in HIC which must be considered when designing care models.

Malaysia has a two-tier primary healthcare delivery system involving both public and private health care providers. These differ in governance, financial arrangement, and types of services provided. The public sector is run by the government and funded by general taxation [17], while the private sector charges fee-for-service. The Malaysian Health System Research project, following an extensive analysis of the health system, found uneven distribution of disease burden and resource allocation between sectors [18][18]. The majority of type 2 diabetes patients were managed in the public primary care setting $[4,5,19]$. Despite that, only a small fraction of total government healthcare expenditures is devoted to primary care; most expenditures fund hospital care [20]. An attempt was made to reform the public primary healthcare services in 2016 , as part of a global effort to reduce the prevalence of non-communicable diseases (NCDs).

An integrated care model consisting of multifaceted interventions known as Enhanced Primary Healthcare (EnPHC) was introduced to 20 public primary health care clinics as a demonstration project. The EnPHC interventions aim to improve existing health care services while making efficient use of existing infrastructure and human resource [21].

In parallel, an impact evaluation of EnPHC consisting of an evaluation at the community and at the primary care facility level was conducted. A process evaluation was also performed at the primary care facilities to improve implementation of the interventions. The primary objective of this study was to evaluate the effectiveness of EnPHC interventions on process of care in type 2 diabetes patients in 
primary care facilities. We also aimed to determine the effectiveness of EnPHC in improving intermediate clinical outcomes in type 2 diabetes.

\section{Methods}

\section{Study Design}

We conducted a quasi-experimental controlled study in 20 intervention and 20 control clinics in two states in the central region (Selangor) and the southern region (Johor) in Malaysia. The clinics were matched and randomly allocated to intervention or control arm by coin flip[22]. The selected clinics served populations of between 12,069 and 500,000 individuals with daily attendances of between 150 and 800 patients. They were located in rural areas or small towns, and had either a permanent or a visiting Family Medicine Specialist (FMS). ArcGIS software was used to ensure that the matched clinic pairs were in different districts to minimize possible contamination [23].

\section{EnPHC Interventions}

The EnPHC interventions implemented in the 20 intervention clinics beginning in July 2017 encompassed: i) an Integrated Care Pathway (ICP); ii) a patient visit checklist; iii) Integrated Specialized Services (ISS) by allied health professionals; iv) NCD screening and cardiovascular risk stratification; v) an NCD care form; vi) the Family Health Teams (FHT) concept; vii) involvment of a care coordinator; viii) pharmacist-led Cardiovascular Care Bundle Medication Therapy Adherence Clinic (CCBMTAC); ix) clinical and prescribing audits; and $\mathrm{x}$ ) structured communication across primary and secondary care levels with a fast track referral system. Further details on the study design and EnPHC interventions have been described elsewhere [8].

\section{Theoretical model for the evaluation}

Figure 1 shows our theoretical model for this evaluation study, which was drawn from Donabedian's Social Cognitive Theory model, the TRIAD model, and a local study [24-27]. EnPHC interventions were targeted at the health care system and health care providers within the clinics. Hence, we incorporated EnPHC interventions as one of the facility factors in this theoretical model. In addition, clinic type was a proxy for the availability of equipment and workload of a clinic. We hypothesised that EnPHC interventions will improve the process of care through health care providers' behaviour changes, which would in turn improve patients' behaviour and ultimately clinical outcomes. Clinical outcomes may be influenced directly by patient factors or indirectly through improved process of care and associated changes in patients' behaviour.

Figure 1 - Theoretical model of the study.

Subjects

All Malaysian patients aged 30 years and above with a documented diagnosis of type 2 diabetes who visited the study clinics for diabetes management within the month of interest were included in the study. Pregnant women were excluded as the management of gestational diabetes follows a separate care pathway.

\section{Sample size calculation}

With a sample of 1800 patient visits, we had $80 \%$ power to detect a relative increase of $28 \%$ in the proportion of patients receiving an annual $\mathrm{HbA} 1 \mathrm{c}$ from the baseline proportion of $52.5 \%$.

\section{Data Extraction}

Data were collected from November 2016 to June 2017 for the pre-intervention period and from October 2018 to June 2019 for the postintervention period. Repeated cross-sectional data were created for each monthly time point based on the most comprehensive list of patient visits available in an individual clinic (either the patient register or appointment book). In terms of the timing, there are 25 periods (in month) of data in total: eight periods before and 17 periods after the intervention with 15 months look-back period to let the changes occur. Medical records of eligible patients were retrospectively sampled using systematic random sampling and data were extracted using a mobile tablet. To ensure data quality, we recruited and trained personnel with medical background for data extraction, incorporated validation rules in the electronic data extraction form and performed real-time data quality checks.

\section{Outcomes}

The main outcomes evaluated in this study were process of care and intermediate clinical outcomes for type 2 diabetes patients. We measured 14 process indicators based on recommendations from the Malaysian Clinical Practice Guideline for Type 2 Diabetes (5th 
Edition)[28] which comprised laboratory investigations, clinical assessments, counselling and prescription. Measures of recommended laboratory investigations were: i) $\mathrm{HbA1c}$ test within the past three months; ii) glucose test (fasting blood glucose (FPG) or random blood glucose (RBG)) at every visit; iii) lipid test (total cholesterol (TC) or triglycerides (TG)) in the past year; iv) LDL test in the past year; v) urine protein or urine microalbumin (UMA) test in the past year; and vi) liver function test (LFT) in the past year. Measures of clinical assessments were: vii) blood pressure (BP) measurement at every visit; viii) BMI measured in the past six months; ix) fundus examination in the past year; $x$ ) foot examination (ulcer, neurological and vascular assessment) in the past year; and xi) cardiovascular disease (CVD) risk assessment using the Framingham Risk Score in the past year. Counselling and prescription measures consisted of: xii) exercise counselling; xiii) diet counselling; xiv) lipid lowering drug prescription. For intermediate clinical outcomes, we measured the percentages of type 2 diabetes patients who achieved the following targets: i) $\mathrm{HbA} 1 \mathrm{c} \leq 7 \%$ (53 mmol/mol); ii) BP $\leq 135 / 75 \mathrm{mmHg}$; iii) LDL $\leq$ $2.6 \mathrm{mmol} / \mathrm{L}$ and iv) $\mathrm{HDL}>1.0 \mathrm{mmol} / \mathrm{L}$ (male) or HDL > $1.2 \mathrm{mmol} / \mathrm{L}$ (female).

\section{Data Analysis}

We used difference-in-differences (DID) analysis to determine the effect of EnPHC interventions in intervention compared to control clinics. Data from November 2016 until June 2017 were grouped to create baseline measures, while a subsequent 15-month phase-in period allowed for the intervention to reach full implementation. Data from October 2018 until June 2019 were pooled to estimate postintervention outcomes. We conducted univariate comparisons of pre-intervention characteristics between the intervention and control groups using the independent t-tests, Wilcoxon rank sum tests, or chi-square tests depending on the data type. Next, we used generalized estimating equations (GEE) to obtain adjusted estimates on the effectiveness of the intervention, while accounting for clustering effects within the clinics. Patient and clinic level covariates stated in the theoretical model were added to the models to adjust for confounders. The "parallel trends" assumption was tested statistically to ensure internal validity (see Additional file 1). A Benjamin-Hochberg correction was applied for multiple testing adjustment on all outcomes.

We used R software, version 3.0.1 [29] to analyse our data. The "geeglm" function from the "geepack" package [30] in R were used to perform the DID analysis.

\section{Results}

A total of 6719 type 2 diabetes patients were identified in the pre-intervention phase and 5298 in the post-intervention phase. Table 1 shows the pre-intervention characteristics of patients in the intervention and control groups. Type 2 diabetes patients in both groups were predominantly women with a mean age of 60 years. The intervention group had more patients of Malay and Chinese ethnicity and fewer patients with dyslipidaemia as comorbidity. There were slightly more patients with newly diagnosed type 2 diabetes in the control group (11.0\%, vs $9.0 \%$ in the intervention group). The median $\mathrm{HbA} 1 \mathrm{c}$ was also higher in the control group (8.0\% or $64 \mathrm{mmol} / \mathrm{mol}) \mathrm{compared} \mathrm{to}$ the intervention group $(7.7 \%$ or $61 \mathrm{mmol} / \mathrm{mol})$. The median $\mathrm{HbA} 1 \mathrm{c}$ was $7.8 \%(61 \mathrm{mmol} / \mathrm{mol})$ in the control group and $7.5 \%$ (58 $\mathrm{mmol} / \mathrm{mol}$ ) in the intervention group in the post-intervention period (not shown in table). The mean BMI of patients in both groups was $28 \mathrm{~kg} / \mathrm{m} 2$, which falls into the obese category.

Table 1: Pre-intervention patient characteristics 


\begin{tabular}{|c|c|c|c|c|c|}
\hline \multirow[t]{3}{*}{ Patient Characteristics } & \multicolumn{2}{|l|}{$N(\%)$} & \multicolumn{2}{|l|}{$N(\%)$} & \multirow[t]{2}{*}{ P-value } \\
\hline & Interve & tion group & Contr & group & \\
\hline & 3283 & & 3436 & & \\
\hline Age $(\text { years })^{\mathrm{a}}$ & 60.0 & $(11.0)$ & 59.8 & $(10.8)$ & 0.526 \\
\hline Male & 1183 & $(36.0)$ & 1302 & (37.9) & 0.115 \\
\hline \multicolumn{6}{|l|}{ Ethnicity } \\
\hline Chinese & 561 & $(17.1)$ & 637 & $(18.5)$ & $<0.001$ \\
\hline Indian & 364 & $(11.1)$ & 469 & $(13.6)$ & \\
\hline Malay & 2343 & $(71.4)$ & 2303 & $(67.0)$ & \\
\hline Others & 15 & $(0.5)$ & 27 & $(0.8)$ & \\
\hline Weight $(\mathrm{kg})^{\mathrm{a}}$ & 69.6 & $(15.3)$ & 69.9 & $(15.6)$ & 0.499 \\
\hline BMI $\left(\mathrm{kg} / \mathrm{m}^{2}\right)^{\mathrm{a}}$ & 28.1 & $(5.6)$ & 28.3 & $(5.9)$ & 0.175 \\
\hline BMI & & & & & 0.685 \\
\hline$<18.5$ & 46 & $(1.6)$ & 46 & (1.5) & \\
\hline $18.5-22.9$ & 385 & (13.3) & 386 & $(12.8)$ & \\
\hline $23-27.4$ & 1046 & $(36.1)$ & 1058 & $(35.1)$ & \\
\hline$>27.4$ & 1421 & $(49.0)$ & 1527 & $(50.6)$ & \\
\hline No target organ damage & 2317 & $(70.6)$ & 2430 & $(70.7)$ & 0.895 \\
\hline Smoking Status & & & & & $<0.001$ \\
\hline Current & 201 & $(6.1)$ & 209 & $(6.1)$ & \\
\hline Ex-smoker & 39 & $(1.2)$ & 56 & $(1.6)$ & \\
\hline Non-smoker & 1111 & $(33.8)$ & 1615 & $(47.0)$ & \\
\hline Unknown & 1932 & $(58.8)$ & 1556 & $(45.3)$ & \\
\hline \multicolumn{6}{|l|}{ Comorbidities } \\
\hline Dyslipidaemia & 1539 & $(46.9)$ & 1733 & $(50.4)$ & 0.004 \\
\hline Hypertension & 2562 & $(78.0)$ & 2693 & $(78.4)$ & 0.738 \\
\hline Newly diagnosed diabetes & 294 & $(9.0)$ & 379 & $(11.0)$ & 0.005 \\
\hline Diabetes duration (years )* & 5 & $(2.6,9.8)$ & 5 & $(2.4,9.9)$ & 0.644 \\
\hline Hypertension duration (years ) * & 7 & $(3.5,11.2)$ & 7 & $(3.3,11.3)$ & 0.306 \\
\hline Dyslipidaemia duration (years ) * & 5 & $(2.9,8.0)$ & 5 & $(2.7,8.0)$ & 0.531 \\
\hline Systolic blood pressure $(\mathrm{mmHg})^{a}$ & 137 & $(18.9)$ & 138 & $(18.8)$ & 0.750 \\
\hline Diastolic blood pressure $(\mathrm{mmHg})^{a}$ & 77 & $(11.2)$ & 78 & $(10.7)$ & 0.144 \\
\hline $\operatorname{LDL}(\mathrm{mmol} / \mathrm{l})^{a}$ & 3.0 & $(1.0)$ & 3.0 & $(1.1)$ & 0.760 \\
\hline $\mathrm{HbA1c}(\%)^{*}$ & 7.7 & $(6.6,9.6)$ & 8.0 & $(6.7,9.7)$ & 0.021 \\
\hline
\end{tabular}

Data are presented as $\mathrm{N}(\%)$ unless otherwise indicated, ${ }^{a}$ mean (standard deviation), * median (interquartile range)

After the EnPHC interventions, there were significant relative changes in seven out of 14 process of care measures in the intervention group as shown in Table 2. Compared to controls, the intervention clinics showed significant improvement in performance of four of six 
laboratory investigations: HbA1c tests in the past three months (OR 3.31, 95\% Cl, 2.13, 5.13), lipid test in the past one year (OR 4.59, 95\% $\mathrm{Cl}, 2.64,7.97)$, LDL test in the past one year (OR 4.33, 95\% Cl, 2.16, 8.70), and UMA test in the past one year (OR 1.99, 95\% Cl, 1.12, 3.55). Conversely, patients in intervention clinics were three times less likely to have a blood glucose test on the day of visit. There was no significant change for LFT (OR 1.08, 95\% Cl, 0.51, 2.27).

There were two improvement observed out of five clinical management measures. BMI measured in the past six months showed improvement with a relative odds of $15.80(95 \% \mathrm{Cl}, 4.78,52.24)$ and CVD risk assessment in the past one year showed a marked increase in the intervention group with a relative odds of $174.65(95 \% \mathrm{Cl}, 16.84,1810.80)$. BP measurement at every visit showed high baseline values ranging from $97 \%-98.9 \%$ in both groups with little room for improvement.. As for counselling and prescription, the intervention group exhibited a significant post-intervention increase in exercise counselling with an odds ratio of 1.18 (95\% $\mathrm{Cl}, 1.04,1.33)$. Although a higher odds of dietary counselling was observed in the intervention group, it was not significant $(\mathrm{OR} 1.86,95 \% \mathrm{Cl}, 1.02,3.38)$. Use of lipidlowering medication exhibited high baseline values of over $98 \%$ in both groups with no significant change after the intervention (OR 0.97 , $95 \% \mathrm{Cl}, 0.22,4.31)$.

Three of four intermediate clinical outcomes showed improvement (i.e., HbA1c, LDL and HDL within target range), but none of the changes were statistically significant. Detailed results are shown in Table 3.

Table 2: Difference-in-difference (DID) analysis of EnPHC interventions on process of care in Type 2 Diabetes patients 


\begin{tabular}{|c|c|c|c|c|c|c|c|c|c|c|}
\hline \multirow[t]{3}{*}{ Outcome (\%) } & \multirow{3}{*}{$\mathbf{N}^{\mathbf{a}}$} & \multicolumn{2}{|c|}{$\begin{array}{l}\text { Intervention } \\
\text { Group }\end{array}$} & \multicolumn{2}{|c|}{ Control Group } & \multirow{3}{*}{$\begin{array}{l}\text { Difference } \\
(C=A-B)\end{array}$} & \multirow[t]{3}{*}{$\mathrm{OR}^{\mathrm{b}}$} & \multirow{3}{*}{$\begin{array}{l}95 \% \mathrm{Cl} \\
\text { (Lower } \\
\text { Cl) }\end{array}$} & \multirow{3}{*}{$\begin{array}{l}95 \% \text { Cl } \\
\text { (Upper } \\
\text { Cl) }\end{array}$} & \multirow{3}{*}{$\begin{array}{l}\text { Adjusted } \\
\text { P-value }^{e}\end{array}$} \\
\hline & & \multirow[t]{2}{*}{ Pre } & $\begin{array}{l}\text { Change } \\
\text { (A) }\end{array}$ & \multirow[t]{2}{*}{ Pre } & \multirow{2}{*}{$\begin{array}{l}\text { Change } \\
\text { (B) } \\
\text { (Post- } \\
\text { Pre) }\end{array}$} & & & & & \\
\hline & & & $\begin{array}{l}\text { (Post- } \\
\text { Pre) }\end{array}$ & & & & & & & \\
\hline \multicolumn{11}{|l|}{ Lab investigations } \\
\hline $\begin{array}{l}\mathrm{HbA} 1 \mathrm{c} \text { test in the past } 3 \\
\text { months }^{\mathrm{d}}\end{array}$ & 10803 & 38.4 & 23.2 & 36.2 & -5.6 & 28.8 & 3.306 & 2.131 & 5.130 & $<0.001$ \\
\hline $\begin{array}{l}\text { Blood glucose test at } \\
\text { every visit }{ }^{d}\end{array}$ & 10821 & 82.4 & -30.2 & 84.9 & -4.5 & -25.7 & 0.323 & 0.142 & 0.737 & 0.018 \\
\hline $\begin{array}{l}\text { Lipid test in the past one } \\
\text { year }^{d}\end{array}$ & 10821 & 83.3 & 13.6 & 78.8 & 3.5 & 10.1 & 4.587 & 2.640 & 7.970 & $<0.001$ \\
\hline $\begin{array}{l}\text { LDL test in the past one } \\
\text { year }\end{array}$ & 10820 & 70.2 & 22.4 & 69 & 2.6 & 19.8 & 4.331 & 2.157 & 8.700 & $<0.001$ \\
\hline $\begin{array}{l}\text { UMA test in the past } \\
\text { one year }\end{array}$ & 10802 & 65.9 & 15.9 & 67.8 & 2.1 & 13.8 & 1.994 & 1.119 & 3.553 & 0.038 \\
\hline $\begin{array}{l}\text { Liver function test in } \\
\text { the past one year }{ }^{d}\end{array}$ & 10821 & 58.2 & 3.0 & 51.3 & 1.8 & 1.2 & 1.084 & 0.518 & 2.269 & 0.894 \\
\hline \multicolumn{11}{|l|}{ Clinical assessments } \\
\hline $\begin{array}{l}\text { Blood pressure at every } \\
\text { visit }\end{array}$ & 10821 & 97.4 & 1.1 & 98.9 & 0.4 & 1.5 & 3.207 & 0.794 & 12.962 & 0.159 \\
\hline $\begin{array}{l}\text { BMI measured in the } \\
\text { past six month }{ }^{c, d}\end{array}$ & 11945 & 29.0 & 49.5 & 50.8 & -12.5 & 62.4 & 15.80 & 4.78 & 52.24 & $<0.001$ \\
\hline $\begin{array}{l}\text { Fundus examination in } \\
\text { the past one year }{ }^{d}\end{array}$ & 10479 & 38.5 & -1.3 & 37.7 & -8.9 & 7.6 & 1.325 & 0.778 & 2.256 & 0.420 \\
\hline $\begin{array}{l}\text { Foot examination in the } \\
\text { past one year }{ }^{d}\end{array}$ & 10695 & 42.5 & -8.1 & 52.6 & -3.8 & -4.3 & 0.742 & 0.333 & 1.655 & 0.593 \\
\hline $\begin{array}{l}\text { CVD risk assessment } \\
\text { the past one year }{ }^{d}\end{array}$ & 10821 & 0.6 & 86.3 & 0.1 & 0.8 & 85.5 & 174.654 & 16.840 & 1810.800 & $<0.001$ \\
\hline \multicolumn{11}{|l|}{$\begin{array}{l}\text { Counselling and } \\
\text { prescription }\end{array}$} \\
\hline Exercise counselling ${ }^{d}$ & 10821 & 44.9 & 21.8 & 44.9 & 4.7 & 17.1 & 1.18 & 1.044 & 1.330 & 0.018 \\
\hline Diet counselling ${ }^{d}$ & 10821 & 67.6 & 14 & 63.0 & 3.5 & 10.5 & 1.862 & 1.026 & 3.377 & 0.071 \\
\hline $\begin{array}{l}\text { Lipid lowering drug } \\
\text { prescription d }\end{array}$ & 8835 & 98.0 & 0.3 & 98.4 & -0.3 & 0.6 & 0.969 & 0.218 & 4.308 & 0.968 \\
\hline
\end{tabular}

OR, Odds ratio, UMA, Urine microalbumin, CVD, Cardiovascular disease

${ }^{\text {a }}$ Complete case analyses were performed

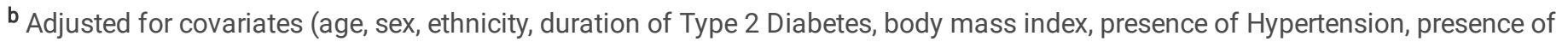
Hyperlipidemia, presence of target organ damage, state, urban/rural, clinic type)

${ }^{c}$ Adjusted for covariates (age, sex, ethnicity, duration of Type 2 Diabetes, presence of Hypertension, presence of Hyperlipidemia, presence of target organ damage, state, urban/rural, clinic type)

${ }^{\mathrm{d}}$ Parallel assumption met 
e P-value adjustment using Benjamin \& Hochberg (1995) method

Table 3: Difference-in-difference (DID) analysis of EnPHC interventions on intermediate clinical outcomes in Type 2 Diabetes patients

\begin{tabular}{|c|c|c|c|c|c|c|c|c|c|c|}
\hline \multirow[t]{3}{*}{ Outcome (\%) } & \multirow[t]{3}{*}{$\mathrm{N}^{\mathrm{a}}$} & \multicolumn{2}{|c|}{$\begin{array}{l}\text { Intervention } \\
\text { Group }\end{array}$} & \multicolumn{2}{|c|}{ Control Group } & \multirow[t]{3}{*}{$\begin{array}{l}\text { Difference } \\
(\mathrm{C}=\mathrm{A}-\mathrm{B})\end{array}$} & \multirow[t]{3}{*}{$O R^{b}$} & \multirow{3}{*}{$\begin{array}{l}95 \% \text { C } \\
\text { (Lower } \\
\text { Cl) }\end{array}$} & \multirow[t]{3}{*}{$\begin{array}{l}95 \% \mathrm{Cl} \\
\text { (Upper Cl) }\end{array}$} & \multirow{3}{*}{ P-value ${ }^{d}$} \\
\hline & & \multirow[t]{2}{*}{ Pre } & $\begin{array}{l}\text { Change } \\
\text { (A) }\end{array}$ & \multirow[t]{2}{*}{ Pre } & \multirow{2}{*}{$\begin{array}{l}\text { Change } \\
\text { (B) } \\
\text { (Post- } \\
\text { Pre) }\end{array}$} & & & & & \\
\hline & & & $\begin{array}{l}\text { (Post- } \\
\text { Pre) }\end{array}$ & & & & & & & \\
\hline$\underset{c}{\mathrm{HbA} 1 \mathrm{c} \leq 7 \%}$ & 9195 & 35.1 & 3.2 & 33.0 & 0.8 & 2.4 & 1.056 & 0.8394 & 1.328 & 0.672 \\
\hline $\begin{array}{l}\mathrm{BP} \leq \\
135 / 75 \mathrm{mmHg} \\
\mathrm{c}\end{array}$ & 10821 & 27.0 & -2.9 & 27.0 & -0.8 & -2.1 & 0.900 & 0.705 & 1.253 & 0.672 \\
\hline $\begin{array}{l}\mathrm{LDL} \leq \\
2.6 \mathrm{mmol} / \mathrm{L}^{\mathrm{c}}\end{array}$ & 8050 & 39.2 & 5.5 & 40.1 & 1.9 & 3.6 & 1.168 & 0.8698 & 1.57 & 0.603 \\
\hline $\begin{array}{l}\text { HDL within } \\
\text { control }\end{array}$ & 10821 & 47.9 & 7.6 & 44.1 & -2.6 & 10.2 & 1.445 & 1.003 & 2.083 & 0.192 \\
\hline
\end{tabular}

OR, Odds ratio, BP, Blood pressure

${ }^{\text {a }}$ Complete case analyses were performed

${ }^{\mathbf{b}}$ Adjusted for covariates (age, sex, race, duration of Type 2 Diabetes, body mass index, presence of Hypertension, presence of Hyperlipidemia, presence of Target organ damage, state, urban/rural, clinic type)

${ }^{c}$ Parallel assumption met

d P-value adjustment using Benjamin \& Hochberg (1995) method

\section{Discussion}

This is the first study in Malaysia where a large scale, complex intervention package targeting improvement in chronic disease management in primary care facilities was evaluated in a real-world setting displaying outcomes which were adjusted for patient- and clinic-characteristics. We found that the EnPHC interventions improved process of care but did not show overall improvements in intermediate clinical outcomes.

Process of care that were evaluated can be categorised into three areas, namely, laboratory investigations, clinical assessment and counselling and prescription. Eight out of 14 indicators showed change after the intervention. The improvements in process of care were most evident for laboratory investigations, which may be attributed to several reinforcing elements of the EnPHC intervention package including physician reminders, standardized documentation and adequate resource allocation in terms of availability of reagents. Although the majority of laboratory investigations improved, there was no change in LFT compared to indicators like HbA1c and urine albumin tests. Of interest, there was a decrease in blood glucose testing on the clinic visit day. Taken together with the observed increase in three-monthly HbA1c tests, we may be witnessing an appropriate shift to more efficient use of manpower and resources, since $\mathrm{HbA} 1 \mathrm{c}$ is a more reliable marker of glycemic control.

In the area of clinical assessments, we saw an increase in the proportion of BMI measured in the past six month and marked increase in CVD risk assessments completed in the past year while other indicators showed no significant changes. BMI is a method to quantify obesity reflected by access in body fat mass. Frequent monitoring allows prediction of coronary heart disease [31], stroke [32], and cardiovascular death[33] and can be managed in a timely manner. Similar to the increase in CVD risk assessments, although early detection is important, they were neither routinely assessed nor well-documented previously. By making BMI and the CVD risk score a required field in patients' medical records, the interventions managed to reinforce this guideline-adherent practice. Compared to laboratory investigations, clinical assessments are more provider-, resource- and patient-dependent. Improved performance of these assessments is more commonly observed following intervention in high-income countries [34] compared to LMICs [13, 14]. On the other hand, the lack of 
improvement in fundus and foot examinations may be due to insufficient manpower and equipment. The fundamental objectives of the EnPHC included task-shifting and staff empowerment with minimal increase in staffing or resources. As a result, a complex intervention such as this may have increased workload and required trickle-down training in an environment where staff turnover is high. Indeed, an accompanying survey of health care providers revealed low job satisfaction in the EnPHC clinics [35]. Inadequate equipment may be another reason for lack of improvement in fundus examination. Finally, our study may underestimate improvement in foot examination as our definition required documentation of all three examinations (ulcer, neurological and vascular) to be considered a complete foot assessment.

In the area of counselling and prescription, only one of three indicators showed significant improvement. We examined the areas of providing lifestyle advice through exercise and diet counselling and use of lipid-lowering medication as proxies for preventive actions by health care providers. Measures of exercise and diet counselling both moved in a positive direction in the intervention group; the change was not significant for diet counselling. These improvements may also be due to the reinforcing elements of the EnPHC intervention mentioned above. Prescribing of lipid lowering medication did not show improvement following the intervention, primarily due to high baseline prescription rates in both study groups which left little room for improvement.

The majority of process of care in the EnPHC clinics showed improved performance with the exceptions of those that required substantially more time from health care providers. This findings was further supported by the EnPHC process evaluation that showed there was initial readiness, however sustainability of the intervention was challenging. Some barriers identified were poor clinic infrastructure, staff shortages and inadequate training [36].

Although the odds of achieving recommended targets were higher for three out of four intermediate clinical outcomes (HbA1c, LDL and $\mathrm{HDL}$ ) in the intervention group, the improvements were not statistically significant. This is in line with conceptual models which posit that process of care contribute less to patient outcome than patient factors [37]. Improving the intermediate clinical outcomes would require not only identification of patients with elevated clinical biomarkers, but also health care providers' responding with appropriate medications and self-management support followed by patients' adherence to the recommended therapies and lifestyle changes. A system and health care provider targeted intervention such as EnPHC may may need longer duration of implementation and greater patient engagement to bring about the more distal changes in patient outcomes. It is likely that the intervention did not adequately address patient level factors [38] through self-management support, a component which was commonly included in other studies that found improvement in patient outcomes $[12,15]$. This is an area for potential improvement in the EnPHC package, given that low level of self-management support was reported in the Malaysian primary care setting [39]. Additionally, the lack of improvement in HbA1c may be due in part to the relatively low median pre-intervention $\mathrm{HbA} 1 \mathrm{c}$ in our study $[11,40]$. A systematic review has suggested that interventions targeting the health system and health care providers seem to be more beneficial when baseline HbA1c control is poor [11]. In our study, there was a uniform reduction in median $\mathrm{HbA} 1 \mathrm{c}$ in both intervention and control in the post-intervention period suggesting that it could either be due to continuous improvement in clinical care over time or a spillover effect from the intervention clinics.

There are several limitations in this study. Four indicators did not meet the parallel trends assumption as shown in Additional file 1; these results should be interpreted with caution. Missing records and incomplete documentation in patient records may have introduced selection bias. The data collected were based on documentation in medical records and thus may underestimate the frequencies of care process that were carried out but not documented. The strength of our study is that selection bias was controlled through several steps. Important clinic characteristics were matched to limit between-group differences in resource availability and capacity. Probability sampling of medical records ensured representativeness of the sample with inclusion of all type 2 diabetes patients who were compliant with their clinic follow-up. We ensured continuous monitoring for the presence of other health programs in the clinics throughout the duration of the evaluation which could have contaminated the effects of the EnPHC intervention. In addition, the evaluation was carried out by investigators who were independent from the implementation team to minimize biases. Another strength is that in addition to process of care, we also measured patient intermediate outcomes for a more comprehensive assessment of quality of care.

\section{Conclusion}

The EnPHC interventions were able to change health care providers' behaviours which are the first step towards improved quality of care. However, patient behavior change is challenging and may require greater engagement to translate into improved intermediate clinical outcomes. Hence, health system and health care provider level interventions may take longer to have an effect on intermediate clinical outcomes. Adding components to EnPHC interventions that can improve patient engagement and facilitate self-management should be considered before nationwide scale-up. Future research should assess the implementation and cost-effectiveness of the EnPHC interventions, as well as consistency across settings in its content, intensity and effects.

Page $10 / 14$ 


\section{Declarations}

\section{Ethical approval}

This study was approved by the Medical Research and Ethics Committee, Ministry of Health Malaysia (NMRR-17-267-34768).

\section{Consent for publication}

Not applicable

\section{Availability of data and materials}

The data that support the findings of this study are available from the corresponding author, upon reasonable request.

\section{Competing interests}

The authors declare that they have no competing interests.

\section{Funding}

This EnPHC-EVA: Facility study was funded by a grant from the Ministry of Health Malaysia (NMRR-17-267-34768) under the MHSR initiative. The sponsor had no role in the design, data collection, analysis and interpretation of data or preparation of this manuscript.

\section{Author contributions}

MH, SSivasampu, XRT, CLC, SMO and YMFL conceived the idea for the manuscript. RA, DK, DRD, AW ,NHN and NII contributed to the design of the study. RA, DK, DRD supervised the study. With contributions by DRD and AKW,MH, XRT, SHA, and CLC carried out the data analysis. XRT, SHA, MH, CLC, MTL, SShanmugam, FSAJ, NK,YMFL, NHN, NII contributed to the coordination of the study. MH, SSivasampu, XRT, CLC and SMO drafted the manuscript. XRT, CLC, NK, SHA, MH, MTL, SShanmugam, FSAJ, NK and YMFL made substantial contributions to the acquisition of the data. All authors critically revised the manuscript. All authors read and approved the final manuscript. SSivasampu takes full responsibility for the contents of the article.

\section{Acknowledgments}

The authors thank the Director-General of Health Malaysia for supporting this study. We also acknowledge the contribution of the EnPHCEVA: Facility team, EnPHC Project Management Team, the Johor and Selangor state liaison officers, and all health care providers and patients in the forty clinics for their roles in data collection. We are also grateful to Professor Tong Seng Fah, Dr Mastura Ismail, Dr Salmah Nordin, and Dr Nik Halina for their comments on the findings.

\section{References}

1. Seuring T, Archangelidi O, The Economic Costs of Type 2 Diabetes: A Global Systematic Review. PharmacoEconomics, 2015. 33(8): p. 811-831.

2. Global, regional, and national comparative risk assessment of 84 behavioural, environmental and occupational, and metabolic risks or clusters of risks for 195 countries and territories, 1990-2017: a systematic analysis for the Global Burden of Disease Study 2017. Lancet, 2018. 392(10159): p. 1923-1994.

3. Bommer C, Sagalova V, Global Economic Burden of Diabetes in Adults: Projections From 2015 to 2030. Diabetes Care, 2018. 41(5): p. 963-970.

4. (IPH), I.f.P.H., National Health and Morbidity Survey 2015 (NHMS 2015). Vol. II: Non-Communicable Diseases, Risk Factors \& Other Health Problems. Malaysia.

5. Feisul IM, Azmi S, What are the direct medical costs of managing Type 2 Diabetes Mellitus in Malaysia? Med J Malaysia, 2017. 72(5): p. 271-277.

6. Mastura I, Chew BH, Control and Treatment Profiles of 70,889 Adult Type 2 Diabetes Mellitus Patients in Malaysia - A Cross Sectional Survey in 2009 2011; . International Journal of Collaborative Research on Internal Medicine \& Public Health, 2011. 3:98-113.

7. De Pablos-Velasco P, Parhofer KG, Current level of glycaemic control and its associated factors in patients with type 2 diabetes across Europe: data from the PANORAMA study. Clin Endocrinol (Oxf), 2014. 80(1): p. 47-56. 
8. Sivasampu S, Teh XR, Study protocol on Enhanced Primary Healthcare (EnPHC) interventions: a quasi-experimental controlled study on diabetes and hypertension management in primary healthcare clinics. Primary Health Care Research \& Development, 2020. 21: p. e27.

9. Baxter S, Johnson M, The effects of integrated care: a systematic review of UK and international evidence. BMC Health Services Research, 2018. 18(1): p. 350.

10. Lim LL, Lau E, Aspects of Multicomponent Integrated Care Promote Sustained Improvement in Surrogate Clinical Outcomes: A Systematic Review and Meta-analysis. Diabetes Care, 2018. 41(6): p. 1312-1320.

11. Tricco AC, Ivers N, Effectiveness of quality improvement strategies on the management of diabetes: a systematic review and metaanalysis. The Lancet, 2012. 379(9833): p. 2252-2261.

12. Ramli AS, Selvarajaih S, Effectiveness of the EMPOWER-PAR Intervention in Improving Clinical Outcomes of Type 2 Diabetes Mellitus in Primary Care: A Pragmatic Cluster Randomised Controlled Trial. BMC Family Practice, 2016. 17(1): p. 157.

13. Webb EM, Rheeder $\mathrm{P}, \mathrm{A}$ cluster-randomized trial to estimate the effect of mobile screening and treatment feedback on $\mathrm{HbA} 1 \mathrm{c}$ and diabetes-related complications in Tshwane primary health care clinics, South Africa. Prim Care Diabetes, 2017. 11(6): p. 546-554.

14. Steyn K, Lombard C, Implementation of national guidelines, incorporated within structured diabetes and hypertension records at primary level care in Cape Town, South Africa: a randomised controlled trial. Glob Health Action, 2013. 6: p. 20796.

15. Saleh S, Farah A, Using Mobile Health to Enhance Outcomes of Noncommunicable Diseases Care in Rural Settings and Refugee Camps: Randomized Controlled Trial. JMIR Mhealth Uhealth, 2018. 6(7): p. e137.

16. Esterson YB,Carey M, A systematic review of innovative diabetes care models in low-and middle-income countries (LMICs). J Health Care Poor Underserved, 2014. 25(1): p. 72-93.

17. Jaafar S, Mohamad Noh K, Malaysia Health System Review, Health Systems in Transition. World Health Organization; 2013, Vol. 3 No.1.

18. Malaysia Health Systems Research: Contextual analysis of the Malaysian health system. Ministry of Health Malaysia and Harvard University TH Chan School of Public Health. . Putrajaya, Malaysia, 2016. Vol 1.: p. Retrieved from: http://www.moh.gov.my/moh/resources/Vol_1_MHSR_Contextual_Analysis_2016.pdf.

19. Sivasampu S, Lim YMF, National Medical Care Statistics (NMCS) 2014. Kuala Lumpur: National Clinical Research Centre; 2015.

20. Institute of Health Systems Research, M.o.H.M., Malaysia Healthcare Demand Analysis. Inequalities in Healthcare Demand \& Simulation of Trends and Impact of Potential Changes in Healthcare Spending. 2013.

21. Enhanced Primary Healthcare Lab January-March 2017. 2017, MInistry of Health Malaysia: Malaysia.

22. Imai K, King G, The Essential Role of Pair Matching in Cluster-Randomized Experiments, with Application to the Mexican Universal Health Insurance Evaluation. Statist. Sci., 2009. 24(1): p. 29-53.

23. ESRI 2011. ArcGIS Desktop: Release 10. Redlands, CA: Environmental Systems Research Institute.

24. Donabedian A, Evaluating the Quality of Medical Care. The Milbank Quarterly, 2005. 83(4): p. 691-729.

25. Bandura A, Social Cognitive Theory: An Agentic Perspective. Annual Review of Psychology, 2001. 52(1): p. 1-26.

26. Health Systems, Patients Factors, and Quality of Care for Diabetes. Diabetes Care, 2010. 33(4): p. 940.

27. Tong SF, Vethakkan SR, Why do some people with type 2 diabetes who are using insulin have poor glycaemic control? A qualitative study. BMJ Open, 2015. 5(1): p. e006407.

28. Malaysian Clinical Practice Guidelines Management of Type 2 Diabetes Mellitus (5th Edition). 2015. Retrieved from:https://www.moh.gov.my/moh/resources/Penerbitan/CPG/Endocrine/3a.pdf.

29. R Core Team (2020). R: A language and environment for statistical computing. R foundation for statistical computing, Vienna, Australia. URL https://www.R-project.org/.

30. Halekoh U, Højsgaard S, Yan J (2006). “The R Package geepack for Generalized Estimating Equations.” Journal of Statistical Software, 15/2, 1-11.

31. Bogers RP, Bemelmans WJ, Association of overweight with increased risk of coronary heart disease partly independent of blood pressure and cholesterol levels: a meta-analysis of 21 cohort studies including more than 300,000 persons. Arch Intern Med. 2007; 167:17208.

32. Strazzullo P, Delia L, Excess body weight and incidence of stroke: meta-analysis of prospective studies with 2 million participants.Stroke. 2010; 41:e41826. 
33. Mangione CM, Gerzoff RB, The Association between Quality of Care and the Intensity of Diabetes Disease Management Programs. Annals of Internal Medicine, 2006. 145(2): p. 107-116.

34. Wong WJ, Mohd Norzi A, The effects of enhanced primary healthcare interventions on primary care providers' job satisfaction. BMC Health Services Research, 2020. 20(1): p. 311.

35. Rahim I, Low LL, Evaluation of Enhanced Primary Healthcare-Process evaluation (ENPHC-PE). 2019, Institute Health System Research, Ministry of Health Malaysia.

36. Ackermann RT, Thompson TJ, Is the Number of Documented Diabetes Process-of-Care Indicators Associated With Cardiometabolic Risk Factor Levels, Patient Satisfaction, or Self-Rated Quality of Diabetes Care? The Translating Research into Action for Diabetes (TRIAD) study, 2006. 29(9): p. 2108-2113.

37. Lim YMF, Ang SH, Clinic and patient variation in intermediate clinical outcomes for type 2 diabetes: a multilevel analysis. BMC Family Practice, 2019. 20(1): p. 158.

38. Lim MT, Lim YMF, Patient experience on self-management support among primary care patients with diabetes and hypertension. Int $J$ Qual Health Care, 2019. 31(7): p. 37-43.

39. Shojania KG, Ranji SR, Effects of quality improvement strategies for type 2 diabetes on glycemic control: a meta-regression analysis. Jama, 2006. 296(4): p. 427-40.

\section{Figures}

\section{THEORETICAL MODEL}

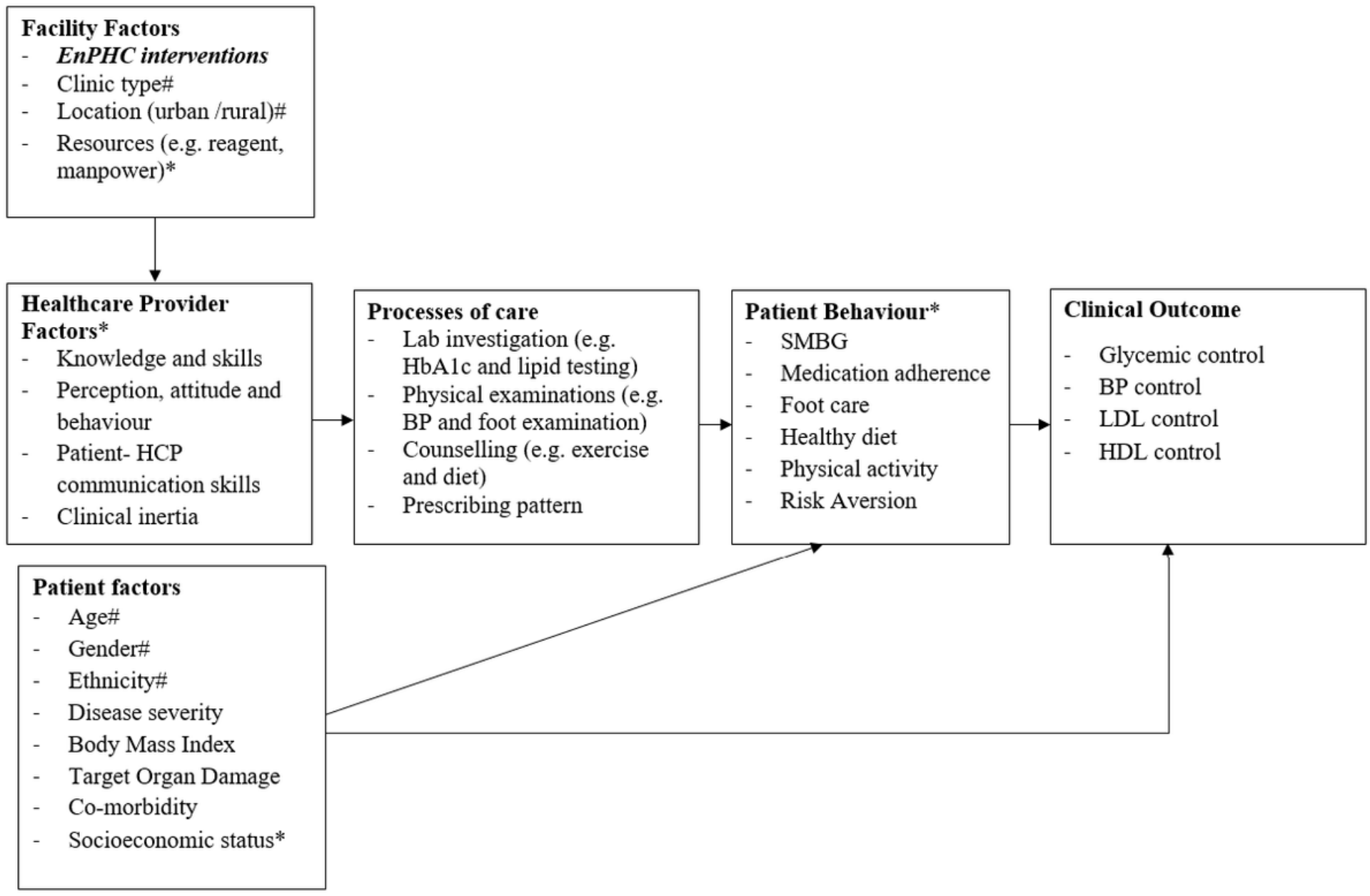

Figure 1

Page $13 / 14$ 
Theoretical model of the study. *= unmeasured outcomes, \#=non-modifiable factors, SMBG: self-monitoring of blood glucose, BP: blood pressure

\section{Supplementary Files}

This is a list of supplementary files associated with this preprint. Click to download.

- 14012021Additionalfile1.docx 